\title{
NEOLIBERALISMO E DESDEMOCRATIZAÇÃO NO BRASIL (1990 - 2016): UMA LEITURA A PARTIR DOS ESTUDOS DE WOLFGANG STREECK
}

\author{
NEOLIBERALISM AND DEDEMOCRATIZATION IN BRAZIL (1990 - 2016): A \\ READING FROM THE STUDIES OF WOLFGANG STREECK
}

DOI: 10.5380/cg.v9i2.7580o

Maria Raphaela Campello

Brenda Fontana3

\begin{abstract}
Resumo
Partindo da análise de Wolfgang Streeck sobre a Europa, este artigo busca demonstrar como o avanço do neoliberalismo no Brasil - a despeito das especificidades de cada caso - teve efeitos igualmente corrosivos para a democracia. A partir da reconstrução histórica das políticas e reformas realizadas por Collor, FHC, Lula e Dilma, observa-se que a cartilha neoliberal, ao mesmo tempo que contribuiu para a desindustrialização de nossa economia, alienou também a população das decisões sobre a condução da política econômica ao longo das três décadas sobre as quais nos debruçamos. Dessa maneira, tal como na Europa, as tentativas estatais de conciliar justiça de mercado e justiça social explicitaram os limites do capitalismo democrático no Brasil.
\end{abstract}

Palavras-Chave: Neoliberalismo; Democracia brasileira; Capitalismo democrático; Wolfgang Streeck.

\begin{abstract}
Based on Wolfgang Streeck's analysis of Europe, this article seeks to demonstrate how the advance of neoliberalism in Brazil - despite the specificities of each case - had equally corrosive effects on democracy. Resting on the policies and reforms carried out by Collor, FHC, Lula and Dilma, it's argued that the neoliberal reforms, while contributing to the deindustrialization of our economy, has also excluded the population from decisions regarding the economic policy over the three decades that we analyzed. In this way, as in Europe, state attempts to reconcile market and social justice brought to light the limits of democratic capitalism in Brazil.
\end{abstract}

Keywords: Neoliberalism; Brazilian democracy; Democratic capitalism; Wolfgang Streeck.

\section{INTRODUÇÃO}

Nesse artigo, considera-se a sistematização do economista alemão Wolfgang Streeck (2014) sobre a complexa relação entre capitalismo e democracia nos países centrais europeus para discutir

${ }^{1}$ O presente trabalho foi realizado com apoio da Coordenação de Aperfeiçoamento de Pessoal de Nível Superior - Brasil (CAPES) - Código de Financiamento 001.

${ }^{2}$ Bacharel em História (UFMG) e Relações Internacionais (PUC Minas), mestranda em Ciência Política (USP), na área de Teoria Política e História do Pensamento Político. E-mail: mariacampello@usp.br. ORCID: https://orcid.org/0000-0002-8940-3564.

${ }_{3}$ Bacharel em Relações Internacionais (PUC Minas) e Pesquisadora do Grupo de Estudos de Relações Internacionais do Atlântico Sul (PUC Minas). E-mail: brendaafontana@gmail.com. ORCID: https://orcid.org/0000-0002-7333-9684. 
a situação brasileira. Partindo da concepção de que os países europeus vêm tentando, a duras penas, conciliar os interesses de um mercado financeiro em expansão predatória com as demandas por justiça social do povo, pretende-se investigar como se deu o avanço da agenda neoliberal dentro do Brasil e quais suas consequências para a democracia brasileira.

Seguindo o quadro analítico proposto por Streeck (2011a, 2012b), utiliza-se do método histórico-dedutivo (exercitado tanto pela escola histórica alemã quanto por Bresser-Pereira) para reconstruir o processo de introdução do receituário neoliberal no Brasil. Como argumenta Streeck (2012b), é preciso uma análise econômica que traga a sociologia de volta para o centro, uma que se situe entre a sociologia econômica e a economia política. O capitalismo, para o autor, deve ser encarado não como uma economia, mas uma sociedade; como um "sistema de ação social e um conjunto de instituições que se situa antes no domínio do sociológico que naquele da teoria econômica padrão”. (STREECK, 2012b, p. 2, tradução nossa4).

Se o capitalismo denota uma economia e uma sociedade, estudá-lo requer um quadro conceitual que não os separe. Para mais, requer encará-lo não como um sistema econômico estático e autônomo da sociedade, mas, sim, como uma ordem social histórica em constante evolução, um complexo dinâmico de condicionantes institucionais, oportunidades, expectativas, direitos, recursos e poderes. Considerar o capitalismo como uma economia, apenas, significaria subestimar o peso que possuem, na sociedade capitalista contemporânea, os imaginários e as expectativas. O capitalismo, aqui, é uma história, uma cultura, uma polity (cindida pela tensão entre uma economia moral e uma economia de mercado) e um modo de vida. Essa abordagem enfatiza a evolução e a diferenciação do capitalismo no tempo, em detrimento de uma análise frequente na economia política comparativa contemporânea focada nas diferenças entre os "capitalismos" no espaço geográfico. A perspectiva do autor lança luz sobre as dinâmicas comuns (pois congênitas) das economias políticas capitalistas, para as tensões e conflitos generalizados no desenvolvimento das estruturas sociais sob o capitalismo. (STREECK, 2012b).

Rejeitado o método hipotético-dedutivo, segue-se, então, a tradição histórica do pensamento econômico para analisar a evolução do capitalismo a partir da observação da realidade do Brasil entre 1990 e 2018. Nesse sentido, são observados fatos históricos e sociais, assim como políticas econômicas recentes que se constituíram e consolidaram a partir da década de 1990 no Brasil.

A partir disso, tem-se como hipótese que a penetração do neoliberalismo, iniciada após a Crise da Dívida de $1982^{5}$, teve seu primeiro momento por meio de instrumentos de uma diplomacia

\footnotetext{
4 Texto original: "a system of social action and a set of social institutions falling in the domain of sociological rather than today's standard economic theory".

${ }_{5}$ Neoliberalismo é uma teoria da economia política que define que o bem-estar pode ser melhor alcançado por meio da garantia das liberdades individuais e do mercado. Nessa lógica, o papel do Estado é assegurar o ambiente institucional que viabilize essas liberdades, os direitos de propriedade e a defesa. A ação do Estado deve estar restrita a áreas nas quais o mercado não é capaz de suprir a demanda como por exemplo água, educação, segurança, proteção do meio ambiente e saúde. A partir da década de 1970, as políticas econômicas dos países ocidentais foram fortemente influenciadas pelo receituário neoliberal, concretizado por meio de desregulamentações, privatizações e da diminuição da provisão do Estado em áreas de interesse social.
} 
financeira internacional, sendo aprofundada pelas reformas feitas por Fernando Collor, FHC, Lula e Dilma entre 1990 e 2016, marco temporal deste artigo. No Brasil, tal qual na Europa, parece haver um paulatino e doloroso divórcio entre democracia e capitalismo conforme o Estado procura conciliar os interesses dos dependentes de lucro (no Brasil, os rentistas e os industriais) e dos dependentes de salários. Nesse processo, a justiça de mercado, suas regras e seu ideário passam a imperar sobre os controles da democracia, distanciando a política econômica do terreno das pessoas comuns. Destarte, guardadas as inúmeras especificidades das situações brasileira e europeia, o neoliberalismo, lá e cá, teria efeitos nocivos para a democracia, uma vez que seu aprofundamento significou uma separação definitiva entre o povo e os processos de decisão democráticos sobre a economia.

Para realizar essa análise, na segunda seção deste trabalho discute-se o avanço neoliberal na Europa e o marco teórico-analítico proposto por Streeck. Na terceira seção, busca-se identificar se os movimentos percebidos por Streeck (a saber, aqueles em que Estados colocam em prática instrumentos de economia criativa, injetando recursos a princípio inexistentes na economia para garantir que os mercados continuem operando de acordo com suas preferências) exercem algum tipo de impacto no Brasil. Em seguida, os processos e políticas que conduziram ao aprofundamento do neoliberalismo são reconstituídos, bem como suas consequências para a democracia brasileira.

\section{LIMITES DO CAPITALISMO DEMOCRÁTICO NA EUROPA}

Ao fim da Segunda Guerra Mundial, o centro do capitalismo global vivenciou um período de crescimento do bem-estar da população que parecia ter resolvido as tensões existentes entre demandas sociais e o sistema produtivo decorrentes das revoluções industriais europeias. Organizados em fortes partidos trabalhistas e sindicatos, trabalhadores europeus pressionaram, com êxito, as instituições políticas, que foram submetidas a um controle popular mais amplo. Isso possibilitou a expansão do Estado de Bem-estar social. Mobilizando o instrumental keynesiano, durante aproximadamente três décadas (os trente glorieuses) os Estados do centro do capitalismo foram capazes de garantir o pleno emprego. (STREECK, 2012a).

Essa situação, contudo, só poderia manter-se mediante intervenção estatal. Pelas leis de mercado, os rendimentos marginais são decrescentes, isto é, conforme capital ou trabalho aumentam, a tendência é de que haja um platô, acima do qual o ganho de produtividade tende a declinar. Isto significa que, aumentando-se constantemente os ganhos do trabalho, não é possível aumentar a produtividade na mesma proporção, resultando na compressão da taxa de lucro. Logo tornou-se claro para os detentores de capital produtivo (na denominação de Streeck, dependentes

(HARVEY, 2007). Para Araujo e Bresser-Pereira (2018), o capitalismo neoliberal corresponde ao liberalismo econômico na era da globalização. 
de lucro) que o arranjo do pleno emprego, se favorável às classes trabalhadoras (para Streeck, os dependentes de salário), não atendia às expectativas de retorno dos dependentes de lucro. (STREECK, 2012a).

Essa tensão se expressa também no plano ideológico, onde predomina, entre os detentores de capital, a ortodoxia neoliberal. Nesse registro, as crises são provocadas pelas intervenções estatais que distorcem os mercados em busca de direitos sociais. O Estado, então, deve agir apenas para blindar o mercado contra intervenções sociais e distributivas. Na contramão do receituário neoliberal, o Estado vinha adotando políticas econômicas keynesianas e contracíclicas, as quais passariam a sofrer fortes críticas conforme os detentores de capital começavam a articular sua atuação política. (KALECKI, 1943).

\subsection{O AVANÇO NEOLIBERAL NOS PAÍSES EUROPEUS}

Nos anos 1970, as quedas das taxas de lucro e de crescimento e o quadro de estagflação que se estruturava após o segundo choque do petróleo consolidaram as condições necessárias para que o liberalismo econômico voltasse a ter proeminência. A reação ao pleno emprego e às pressões dos dependentes de salário foi organizada por uma coalizão de classes formada por rentistas e financistas ameaçando ou efetivamente encerrando suas atividades em países que privilegiassem os interesses dos trabalhadores - inaugurando as greves de investimentos. Essa coalizão era legitimada por economistas e filósofos neoliberais como Friedrich Hayek, Carl Popper, Milton Friedman e James Buchanan. (BRESSER-PEREIRA, 2014) (STREECK, 2014).

A pressão desse grupo resultou em uma primeira tentativa, por parte dos Estados, de acomodar a tensão entre as pressões democráticas (pelo pleno emprego e o Bem-estar) e as pressões do capital. À época, isso foi feito via política monetária expansionista, cujo objetivo era manter os salários sem pressionar a taxa de lucro dos capitalistas. Essa foi a primeira manifestação daquilo que Streeck (2014) denomina “compra de tempo", isto é, a tentativa de se evitar uma crise econômica de grandes proporções (e pacificar os conflitos entre o povo e o mercado) via intervenção estatal e injeção de recursos fictícios na economia.

No final dos anos 1970 e início da década de 1980, esse processo se deu por meio de uma política monetária expansionista, com redução da taxa de juros e seguidas desvalorizações do dólar realizadas por Paul Volker, no comando do Federal Reserve Board, representando o golpe final ao sistema de Bretton Woods ${ }^{6}$ (HARVEY, 2007). Nesse movimento anunciava-se o primeiro passo em direção à blindagem da economia às pressões democráticas, isto é, a desdemocratização da economia por meio da deseconomização da democracia: a democracia torna-se domesticada pelos mercados,

\footnotetext{
${ }^{6}$ Ao fazê-lo, os Estados Unidos determinavam o fim da convertibilidade do dólar em ouro, levando o sistema monetário estabelecido nos acordos de Bretton Woods (1944) ao colapso. A operação transformou o dólar em nova moeda fiduciária mundial.
} 
e não o contrário. Em suma, o que se observa é, pela primeira vez, um giro do Estado no sentido de conciliar dois princípios concorrentes que haviam sido institucionalizados no pós-guerra: a justiça social e a justiça de mercado. Streeck assim os define:

Por justiça de mercado entendo a distribuição do resultado da produção de acordo com a avaliação pelo mercado dos desempenhos individuais dos envolvidos, expressa através dos seus preços relativos. [...] A justiça social, pelo contrário, regese por normas culturais e baseia-se no direito estatutário, não no direito contratual. Rege-se por concepções coletivas de honestidade, equidade e reciprocidade, concede direitos a um nível mínimo de vida, independentemente do desempenho económico e da capacidade de desempenho e reconhece direitos civis e humanos, tais como o direito à saúde, à segurança social, à participação na vida da comunidade, à proteção do emprego, à organização sindical, etc. (STREECK, 2014, loc. 1108-1114, tradução nossa7).

A busca pelo equilíbrio entre princípios antagônicos acima descrita, entretanto, só poderia ser temporária. Seu resultado foi um processo inflacionário nocivo para os cidadãos que exacerbou a desigualdade e promoveu a estagnação da economia. Nas décadas seguintes, o Estado, de maneira similar, recorreu a outros tipos de malabarismos voltados para o abrandamento dos conflitos resultantes da tensão inerente à relação entre a justiça social e a justiça de mercado. $\mathrm{O}$ fez, igualmente, em busca de solucionar problemas provocados pela própria atuação do Estado nesse processo.

Na década de 1980, esse tipo de manobra foi executada por meio do estabelecimento de uma política fiscal expansionista via redução tributária que restringiu a arrecadação estatal e forçou o Estado a endividar-se na tentativa de controlar a crise desencadeada pela inflação. As classes trabalhadoras, então, foram vítimas não apenas do desemprego, que passou a se tornar um problema estrutural, como da desmobilização e desarticulação social promovida por governos como os de Margaret Thatcher, na Inglaterra, e de Ronald Reagan, nos Estados Unidos. Sob o entendimento de que, mantidos os padrões corporativistas, empresários e financistas europeus (a esta altura já articulados de maneira supranacional) perderiam competitividade em uma economia internacional cada vez mais interdependente, iniciou-se um processo de dessindicalização e desregulamentação das relações de trabalho, dos fluxos financeiros, da indústria, da agricultura e da extração de recursos naturais. (STREECK, 2014) (HARVEY, 2007).

Paralelamente, a complexificação das estruturas sociais e as mudanças na configuração do trabalho - fruto da desindustrialização e da expansão do setor de serviços - tornaram o conteúdo dos conflitos de interesse, gradualmente, mais identitário e fragmentado. Isso, por sua vez, afastou

\footnotetext{
7 Texto original: "By market justice, I mean distribution of the output of production according to the market evaluation of individual performance, expressed in relative prices. [...] Social justice, on the other hand, is determined by cultural norms and is based on status rather than contract. It follows collective ideas of fairness, correctness and reciprocity, concedes demands for a minimum livelihood irrespective of economic performance or productivity, and recognizes civil and human rights to such things as health, social security, participation in the life of the community, employment protection and trade union organization".
} 
a esfera do trabalho da arena do conflito distributivo, da disputa democrática pela economia, e contribuiu para o enfraquecimento das formas tradicionais de associação política dos trabalhadores, como os sindicatos. Por outro lado, o endividamento público cumpriu o papel que a desvalorização monetária havia realizado outrora: simular a justiça social por meio da injeção de recursos fictícios na proteção social. Na "era de ouro" do neoliberalismo, a perda de soberania do Estado frente aos mercados financeiros tornava-se evidente conforme o serviço da dívida ganhava proeminência sobre os serviços públicos e a obrigatoriedade da austeridade fiscal tornava-se a narrativa dominante. (STREECK, 2012a) (STREECK; SCHMITTER, 1991). O resultado, contudo, não foi o crescimento prometido pela liberalização mas, sim, o aprofundamento da desigualdade e a desaceleração do crescimento nas economias ocidentais ${ }^{8}$.

Nos anos 1990, observou-se uma terceira tentativa de conciliar as demandas democráticas e os interesses de mercado, promovendo o bem-estar por meio do consumo financiado pelo endividamento privado. Dessa forma, esperava-se superar as consequências da restrição orçamentária estatal para efetivação de políticas sociais e promover o crescimento. O endividamento privado via expansão do crédito, no entanto, levou a uma nova espiral de estagnação e desigualdade na Europa. (STREECK, 2014).

\subsection{CAPTURA DO ESTADO PELO MERCADO}

Streeck (2014) critica o argumento ortodoxo de que a crise das finanças públicas seria resultado de um excesso de democracia. Para ele, não são as demandas democráticas por investimentos estatais no sentido de promover justiça social que causam o endividamento dos Estados europeus, mas, sim, o processo de neoliberalização. Foram os cortes tributários visando a atender às demandas do mercado por expansão do lucro que levaram ao aumento da dívida pública, já que o Estado precisou se endividar para cumprir com seus compromissos de investimento público e gastos sociais.

Já em um segundo momento, o Estado buscou adiar o conflito entre dependentes de lucro e dependentes de salário pela expansão do crédito privado. A explosão da especulação creditícia em

\footnotetext{
${ }^{8}$ No mundo, apenas três países que adotaram o receituário neoliberal cresceram mais nos anos 1990 que na era intervencionista (1950-1980): Argentina, Chile e Uruguai. Desde então, porém, as reformas neoliberais levaram à implosão da economia argentina, com impactos devastadores para o vizinho Uruguai. Já o resultado chileno está mais ligado às medidas não ortodoxas como subsídios às exportações industriais e maior controle de capitais a partir dos anos 1990. No que concerne aos países industrializados, o crescimento caiu de 3\% ao ano entre 1960 e 1980 , para $2 \%$ entre 1980 e os anos 2000. De fato, a Europa continental que teve um crescimento médio da produção por habitante na "Era de Ouro" de 5\% ao ano, viu o crescimento cair pela metade, ou até um terço das décadas seguintes. Já os países em desenvolvimento saíram de um crescimento médio anual de $3 \%$ entre 1960 e 1980 para $1,5 \%$ entre 1980 e 2000 , sofrendo uma desaceleração nos níveis de crescimento ainda maior (CHANG, GRABEL, 2014; PIKETTY, 2014). Em comparação com os anos dourados do capitalismo (1945-1970s), os países ocidentais tiveram menor crescimento econômico, maior instabilidade financeira e intensa concentração de renda no 1\% mais rico da população (ARAUJO, BRESSERPEREIRA, 2018).
} 
2008, porém, escancarou a insustentabilidade da expansão indefinida do crédito privado, ao mesmo tempo em que aprofundou ainda mais o endividamento público, devido aos socorros bilionários concedidos ao setor bancário e financeiro. (STREECK, 2014; BRESSER-PEREIRA, 2010).

Observa-se, portanto, que cada crise teve uma resposta que se desdobrou em uma nova crise. Os ciclos de estagnação, desigualdade e endividamento público e privado levam à necessidade de mais compra de tempo e aumentam a necessidade de despolitização da economia, tirando do povo a capacidade de influir democraticamente sobre as tomadas de decisão econômicas. Uma vez que o Estado endividado necessita garantir a confiança dos seus credores (os donos do capital financeiro) o resultado é a neutralização da democracia pela imposição da justiça de mercado. Nessa lógica, a arena dos conflitos políticos vem sendo deslocada: se no período do pós-guerra o conflito esteve na esfera do trabalho, em seguida ele é alçado à esfera estatal na definição de políticas sociais e, em uma etapa posterior, designado à arena privada, ao mercado financeiro. Paulatinamente, o povo foi excluído das disputas políticas que ocorrem, no limite, entre os financistas e Bancos Centrais de diferentes Estados, numa diplomacia financeira internacional. É assim que se dá a crise do capitalismo democrático europeu. (STREECK, 2014).

Streeck pensa a crise de 2008 como uma etapa desta sequência histórica de crises. Nesse momento, os Estados buscaram restabelecer a confiança do mercado socializando as perdas, em uma forma de resolução política da crise econômica: uma em que os Estados assumem para si as dívidas das grandes instituições financeiras, seguindo-se a austeridade fiscal e o abandono das famílias ao endividamento e desemprego. O colapso financeiro de 2008 revelou os processos e os mecanismos que contiveram a crise de um capitalismo europeu cada vez mais distante da democracia. (RODRIGUES, 2013).

Delineados os contornos do avanço das reformas neoliberais e suas consequências para a democracia nos países europeus, investiga-se, neste trabalho, se crises e decisões nos países ricos desenvolvidos podem ter consequências e impactos em países periféricos como o Brasil. Uma análise mais detida pode sugerir que, mesmo conectadas por um mercado crescentemente globalizado, as economias europeias e brasileira reservam suas especificidades. Na próxima seção (por meio de uma breve descrição dos desdobramentos político-econômicos brasileiros entre o fim do século XX e o início do século XXI, nas linhas do que faz Streeck para os países centrais) pretendemos examinar as consequências do avanço da agenda neoliberal para a democracia no Brasil.

\section{AVANÇO DO NEOLIBERALISMO E BLINDAGEM DA DEMOCRACIA BRASILEIRA}

A despeito das particularidades propriamente brasileiras, chama atenção a similaridade entre o processo europeu descrito por Streeck e aquele que se desenvolveu no Brasil. Assim como na Europa, após um momento de expansão das atividades do Estado no período pós-guerra, iniciou-se, 
no Brasil, uma escalada da liberalização econômica cuja evolução provocou a crescente financeirização ${ }^{9}$ da economia e o endividamento do Estado. Consequentemente, o poder do mercado financeiro sobre o Estado tornou-se cada vez maior, passando a justiça de mercado a preponderar sobre a justiça social. Verifica-se aqui que no Brasil, tal como nos países europeus, ao longo dos anos 2000, a primazia dos interesses de mercado significou a crescente impermeabilização dos debates econômicos às demandas populares, despolitizando-os. Essa seção será dedicada ao detalhamento desse processo.

\subsection{NEOLIBERALISMO: DA EUROPA AO BRASIL}

Assim como nos trinta anos gloriosos do capitalismo na Europa, entre 1950 e 1980, o Brasil também passou por mudanças conduzidas pelo Estado que promoveram um amplo processo de industrialização e rápido crescimento econômico. É interessante notar que foi a compra de tempo inicial realizada pelos governos europeus por meio de política monetária expansionista que viabilizou o financiamento do Milagre Econômico na década de 1970. Os empréstimos de bancos europeus e estadunidenses a juros baixos e o crescimento da demanda europeia financiaram o rápido crescimento econômico do período (BRESSER-PEREIRA, 1991). No final da década de 1970, porém, a estagflação das economias europeias levou à adoção de uma política monetária contracionista, com elevação das taxas de juros, o que ocasionou o rápido e elevado aumento do custo do serviço da dívida dos países latino-americanos.

Dessa forma, a compra de tempo realizada pela Europa e os Estados Unidos nos anos 1970, ao mesmo tempo que parece ter proporcionado o financiamento do Milagre Econômico, desdobrouse na Crise da Dívida Externa da América Latina. Isso porque a queda do preço das commodities e o rápido aumento da dívida externa afetaram a percepção de risco dos banqueiros frente às economias latino-americanas, levando-os a não mais reescalonar suas dívidas (GRIFFITH-JONES; SUNKEL, 1990).

Em 1981, a suspensão da rolagem da dívida brasileira pelo sistema financeiro internacional obrigou o país a declarar moratória técnica enquanto negociava com os bancos e o Fundo Monetário Internacional (FMI). Foi nesse momento que a retórica sobre a dívida como resultado de gastos excessivos, da incapacidade de "colocar a casa em ordem" e, no caso brasileiro, da intervenção estatal ao promover a industrialização por substituição de importações apareceu pela primeira vez no país. Enquanto na Europa Streeck (2014) aponta a União Europeia como o principal órgão internacional que viria a difundir a ideia de que "países preguiçosos", endividados, deveriam promover reformas

\footnotetext{
9 A financeirização de uma economia manifesta-se quando o padrão de acumulação de riquezas ocorre, principalmente, por meios financeiros ao invés de atividades produtivas. Apesar de a acumulação via operações financeiras e bancárias ser recorrente no capitalismo, quando ela apresenta maior liquidez e rentabilidade e menos risco que os ativos produtivos podemos dizer que a economia está passando por um processo de financeirização (BRUNO, 2011).
} 
que os assemelhassem aos países com equilíbrio fiscal, no Brasil esse papel já era desempenhado pelo FMI na década de 1980, promotor de uma verdadeira diplomacia financeira internacional.

Foi o FMI, junto aos credores, quem garantiu a imposição do ajuste estrutural com fins de assegurar o pagamento da dívida externa. Atuou, portanto, ora como uma tecnocracia com autoridade intelectual para prescrever um conjunto de reformas econômicas, ora como um instrumento de colaboração intergovernamental com o objetivo final de evitar perdas por parte dos credores. Streeck (2014) chama atenção para o fato de que a "solidariedade" exigida de organizações internacionais e de países em boas condições fiscais serve, na verdade, não para resgatar os países endividados, mas, sim, seus credores. Sendo essa a lógica, é comum que o suporte financeiro vá para os credores internacionais, não para o país que precisa da ajuda. Assim, essa emergente "solidariedade internacional" traduz-se, na prática, em uma forte austeridade fiscal imposta de cima para baixo e de fora para dentro, com consequências danosas para os cidadãos dos Estados endividados, obrigados eles próprios a arcar com as dívidas contraídas em nome do Estado.

De fato, as exigências impostas pelo FMI ao Brasil tiveram exatamente esse impacto. $\mathrm{O}$ Estado brasileiro assumiu a dívida externa privada para si e a economia passou a conviver com altas taxas de inflação, dívida interna e desaceleração econômica, com o Produto Interno Bruto (PIB) chegando a contrair 3,5\% em 1983. Observa-se, portanto, que a dívida externa provocou a crise fiscal e que ambas estavam no cerne das altas taxas de inflação. Nas tentativas de controlar a escalada inflacionária, o Brasil acabou por ter, entre 1980 e 1993, um regime monetário-financeiro dual e inflacionista constituído de duas moedas ${ }^{10}$. A partir de então, os ganhos inflacionários se tornaram o principal eixo da acumulação financeira (BRESSER-PEREIRA, 1991) (BRUNO et al., 2011).

Em seu primeiro momento, a neoliberalização dos países centrais do capitalismo aparentava estar ligada à Crise da Dívida. De maneira indireta e posterior, entretanto (como se pretende demonstrar a seguir) seus desdobramentos culminaram na imposição da agenda neoliberal, que inicialmente foi promovida pelo FMI em consequência da crise deflagrada no capitalismo central. A longo prazo, isso significou um paulatino processo de financeirização da economia, favorecido pela inércia ou colaboração ativa por parte de sucessivos governos brasileiros. Mais à frente, será argumentado que esses movimentos estão associados intimamente à erosão da democracia brasileira.

\subsection{AVANÇO NEOLIBERAL NO BRASIL}

Para além dos ajustes estruturais do FMI, no início dos anos 1990, o Plano Collor I, que tinha como objetivo o controle da inflação, deu continuidade às reformas neoliberais por meio da abertura

\footnotetext{
${ }^{10}$ A moeda oficial, emitida pelo Estado e que servia como unidade de conta e meio de pagamento; e a moeda financeira-indexada, lastreada pelos títulos públicos, porém emitida de forma endógena e gerida pelo setor financeiro privado. A moeda indexada servia como reserva de valor e era um instrumento de enriquecimento privado conforme ativos de alta liquidez e rentabilidade eram negociados com baixo risco (BRUNO et al., 2011).
} 
comercial, da privatização de 18 estatais e da realização de cortes de pessoal e no funcionalismo público. Apesar de banqueiros e empresários industriais concordarem com o corte de gastos estatais e com a revisão dos direitos trabalhistas, já podia-se perceber alguma resistência das elites nacionais, que temiam perder espaço no mercado com a abertura econômica. (MACIEL, 2011) (GREMAUD; SAES; TONETO JR., 1997).

A inflação só seria controlada no início dos anos 1990, com o Plano Real. O plano inaugurou um novo eixo de acumulação financeira, que passava a dar-se sobre a dívida pública. Em 1996, para compensar o fim dos ganhos financeiros decorrente do controle da hiperinflação, o governo passou a financiar a dívida pública com elevadíssimas taxas de juros ${ }^{11}$. Para pagar esses intermediários, nos anos 1990, a carga tributária foi aumentada de $27 \%$ para 34\%. Isso assegurava a transferência de recursos para os rentistas, mas não necessariamente para a melhoria da qualidade de vida do povo. (DOWBOR, 2017; BRUNO et al., 2011). Assim como observado por Streeck (2014) na Europa, a necessidade de arcar com a dívida pública e assegurar a “confiança dos mercados” levou diferentes governos a priorizarem a justiça de mercado em detrimento da justiça social. Nesse sentido, a recente democracia brasileira já aparentava distanciar-se da garantia dos direitos e das demandas dos cidadãos, ao passo que o poder condicionador das instituições financeiras dava seus primeiros sinais.

A Selic em patamares altos desestimulou tanto os bancos a conceder crédito barato, como acontecia na Europa e nos Estados Unidos, como aos empresários de investir. Os elevados rendimentos sustentados pelos títulos da dívida pública brasileira acabaram por ser um entrave para o desenvolvimento conforme o capital passava a alocar-se em atividades puramente financeiras em detrimento de atividades produtivas. A abertura econômica e o fim dos controles cambiais iniciados por Collor tornaram-se igualmente desafiadores para o capital produtivo: ao manter a taxa de câmbio sobreapreciada ${ }^{12}$, a longo prazo essas políticas acabaram por comprimir o lucro e a competitividade das empresas nacionais. (BRESSER-PEREIRA; OREIRO; MARCONI, 2016).

Em outras palavras, a liberalização e a financeirização da economia brasileira fortaleceram, primordialmente, os fundos de investimento, os bancos nacionais e investidores internacionais, em detrimento do capital produtivo. Na tentativa de conciliar os interesses das elites financeiras (a saber, a manutenção das elevadas taxas de juros), frente às queixas de retração da taxa de lucro por parte da burguesia industrial ${ }^{13}$, os governos de FHC, Lula e Dilma realizaram uma série de reformas

\footnotetext{
${ }^{11}$ Durante o governo FHC os títulos do governo rendiam entre $25 \%$ a 30\%, chegando a render 46\%. (DOWBOR, 2017).

12 A taxa de câmbio permanece apreciada no longo prazo, segundo autores novo-desenvolvimentistas, devido a doença holandesa. A doença holandesa é uma falha de mercado existente em países com recursos naturais baratos e abundantes que geram rendas ricardianas em moeda forte, valorizando a moeda local. Ao apreciar a taxa de câmbio, torna empresas nacionais que possuem tecnologia em estado da arte mundial não competitivas no mercado internacional. Entre 1950 e 1980, de maneira não-intencional, os governos brasileiros neutralizaram a doença holandesa por meio de câmbios flutuantes, tarifas sobre importações e subsídios para exportações de produtos industriais. (BRESSER-PEREIRA; OREIRO; MARCONI, 2016).

13 Ao longo da década de 1990, a Federação das Indústrias do Estado de São Paulo (Fiesp) protestou diversas vezes contra a política de juros e a excessiva abertura comercial realizada pelos governos Collor e FHC. (BOITO JR., 2006).
} 
neoliberais que retiraram direitos da população e entregaram ativos públicos para o setor privado. Essas medidas tinham como objetivo aumentar as possibilidades de lucro dos empresários, muitas vezes prejudicando os trabalhadores.

Nessa lógica, Bruno e Paulani (2019) afirmam que as atuais instituições associadas ao funcionamento do capitalismo brasileiro foram construídas tendo como principal objetivo atender aos interesses dos credores nacionais e internacionais. Os autores asseveram que o rumo do receituário neoliberal

[...] permaneceu praticamente intocado nos governos de FHC e Lula / Dilma, apesar das diferenças que os separam. Isso explica, portanto, a enorme abertura financeira, com a falta de controle sobre os fluxos internacionais de capital (FHC e Lula), a internacionalização do mercado de títulos brasileiro (FHC), concessões fiscais para acionistas e ganhos financeiros de não residentes (FHC), as mudanças legais para dar maiores garantias aos credores do Estado (Lei de Responsabilidade Fiscal do governo FHC) e do setor privado (reforma da Lei de Falências durante o governo Lula), as mudanças no regime geral de previdência social (INSS) e nos próprios regimes dos servidores públicos (governo Lula), e por último, mas não menos importante, a adoção de uma receita macroeconômica focada agressivamente no benefício da riqueza financeira, com base na austeridade fiscal e taxas de juros reais absurdamente altas, geralmente as mais altas no mundo (FHC e Lula) (BRUNO; PAULANI, 2019, p.14, tradução nossa'14).

Assim como nas compras de tempo observadas por Streeck (2014), que buscavam adiar tensões entre a justiça de mercado e a justiça social na Europa, os governos brasileiros parecem buscar, em alguns momentos, fazer o mesmo, porém com maiores limitações. Diferentemente dos países europeus (que possuem baixas taxas de juros), a elevada taxa de juros brasileira, por um lado, tornou a injeção de recursos fictícios na economia mais custosa, aprofundando o endividamento público e privado. Por outro, entrou em conflito com os interesses da burguesia industrial. O Estado, então, teve que conciliar os interesses dos intermediários financeiros com os dos empresários industriais, às custas dos direitos dos trabalhadores.

A promoção de justiça social é limitada e apenas possível em momentos de crescimento econômico. Devido a isso, apesar da constrição dos direitos trabalhistas, o crescimento econômico vivido nos governos Lula permitiu melhorias nas condições de vida do povo brasileiro e viabilizou uma redistribuição de renda às margens ${ }^{15}$. (CARVALHO, 2018). Ainda, como na Europa, o governo

${ }_{14}$ Texto original: "[...] has remained practically untouched throughout the governments of FHC and Lula/ Dilma, despite the differences that separate them. This, therefore, explains the enormous financial openness, with the lack of any control over international capital flows (FHC and Lula), the internationalization of the Brazilian bond market (FHC), tax concessions for shareowners and for the financial gains of non-residents (FHC), the legal changes to give greater guarantees to creditors of the State (Fiscal Responsibility Law from FHC's government) and the private sector (reform of the Bankruptcy Law during Lula's government), the changes in the general social security (INSS) regime and in the public servants' own regimes (Lula government) 15, and last but not least, the adoption of a macroeconomic prescription aggressively focused on the benefit from financial wealth, based on fiscal austerity and absurdly high real interest rates that are often the highest in the world (FHC and Lula)".

15 Mesmo em um cenário internacional favorável e com mais políticas redistributivas feitas pelo Estado do que nos governos anteriores, entre 2001 e 2015 a distribuição de renda foi limitada, uma vez que os 50\% mais 
buscou injetar recursos fictícios na economia por meio da expansão creditícia minorando os efeitos das reformas trabalhistas e da previdência. Resguardadas as particularidades e temporalidades, fazse evidente a tentativa de Lula de, à semelhança do processo europeu sistematizado por Streeck, buscar garantir algum tipo de equilíbrio entre atender minimamente às expectativas de bem-estar da população e não contrariar as reivindicações do grande capital.

Em 2011, o governo Dilma mudou o rumo da política econômica que vinha sendo adotada por Lula ao colocar em prática a nova matriz macroeconômica, ou Agenda Fiesp. (CARVALHO, 2018). Ancorada no capital político de Lula, Dilma realizou desonerações tributárias, reduções da taxa de juros, expansão das linhas de crédito e desvalorizações do real. Agradava, assim, à coalizão produtivista (composta pela classe trabalhadora organizada e os empresários industriais), que em 2011 se queixava da desindustrialização (SINGER, 2015).

Enquanto no governo Lula o investimento público foi fundamental para o crescimento econômico, as desonerações tributárias e os cortes de gastos realizados por Dilma não obtiveram o mesmo resultado. A redução das taxas de juros, além de não ter sido suficiente para fomentar o investimento desse setor, em conjunto com a expansão de crédito fornecido pelo Banco do Brasil e a Caixa Econômica Federal, acabou por afetar os spreads dos bancos privados, sendo criticadas por representantes e analistas do mercado financeiro (OREIRO; D'AGOSTINI, 2017). Ainda em 2013, os industriais que antes advogaram pela Agenda Fiesp começaram a abandonar, progressivamente, o apoio ao governo. O processo de desindustrialização precoce e a financeirização da economia brasileira fez com que o que restou da burguesia industrial tivesse interesses duais: tanto em políticas que favorecem a produção quanto nas que favorecem o rentismo. Não é de se espantar, portanto, que quando a Agenda Fiesp não entregou os resultados esperados, essa burguesia tenha se alinhado aos interesses dos intermediários financeiros e dos bancos, que eram também seus interesses. Segundo Singer (2018):

A dupla condição de industriais e rentistas restringiria o grau de empenho na plataforma produtivista. Como capitão de indústria, o empresário deseja crédito barato, portanto, redução dos juros. No entanto, como proprietário de conglomerado que é também financeiro, aspira a juros altos, que remunerem o dinheiro aplicado (SINGER, 2018, loc. 975).

Dessa forma, sob pressão dos bancos, ainda em 2013, os juros da dívida pública voltariam a subir e, a partir de então, Dilma abandonaria a nova matriz econômica em favor da agenda neoliberal.

\subsection{A EROSÃO DA DEMOCRACIA BRASILEIRA}

pobres tiveram um aumento de apenas $1 \%$ na renda total, passando a deter $12 \%$. Enquanto isso, o $1 \%$ mais rico saiu de $25 \%$ para $28 \%$ e os $40 \%$ intermediários passaram a deter $32 \%$ da renda total, tendo uma contração de 2\% (MORGAN, 2017). 
Reeleito com estreita margem em 2014, o PT teve que enfrentar a desaceleração da economia chinesa e a queda dos preços das commodities. A recessão brasileira que se iniciou nesse ano foi, entretanto, igualmente resultado de uma contração nos investimentos destinados ao aumento da capacidade produtiva devido à baixa demanda e ao endividamento das famílias e das empresas no período anterior (OREIRO, 2017; OREIRO, D'AGOSTINI, 2017). Dowbor (2017) aponta que os elevados juros praticados no Brasil desempenharam papel central nesse travamento da economia, dado que os recursos, que deveriam financiar atividades produtivas, estavam sendo drenados pelo mercado financeiro por meio do endividamento público e privado.

Assim como as crises europeias, a crise brasileira apresentou-se como desdobramento de uma resposta à crise anterior. A excessiva expansão de crédito concedida pelos governos Lula em conjunto com uma política de elevadas taxas de juros iniciada por FHC, se evitaram tensões no passado, no segundo governo Dilma vieram a culminar em uma crise política e econômica. Em outras palavras, as tímidas tentativas de conciliar justiça de mercado e justiça social realizadas pelo PT nunca romperam com o marco estrutural de nossa economia, o que culminou na captura do Estado pelo mercado financeiro.

As desonerações tributárias em conjunto com a Selic elevada e a desaceleração econômica provocaram o aumento da dívida pública. Apesar da redução do crescimento dos gastos públicos em 2015, a dívida pública crescia e mais dinheiro era drenado dos investimentos públicos para os bolsos dos rentistas. Ainda assim, a narrativa do excesso de gastos do governo ganhou força na mídia nacional e contribuía para a defesa do corte de gastos. Em seu segundo mandato, Dilma Rousseff termina por sucumbir às pressões do mercado ao colocar o banqueiro Joaquim Levy no Ministério da Fazenda, abandonando a manutenção dos programas sociais e dos níveis de trabalho e renda defendidos ao longo de sua campanha (DOWBOR, 2017).

Mesmo com a adoção do receituário defendido pelo mercado, no ano de 2016 o ambiente político tornou-se propício ao impeachment. De um lado, pela adoção da agenda neoliberal, Dilma falhou em mobilizar as próprias bases populares e militantes do PT em sua defesa. O PT, por meio das políticas sociais e de distribuição de renda, havia ajudado a criar uma nova classe trabalhadora que, vítima da neoliberalização, ao ingressar na vida proletária durante o governo Lula, passou por um processo de fragmentação, terceirização e precarização.. Dessa maneira, não era capaz de reconhecer-se como classe trabalhadora e sinalizou adesão aos valores da classe média - ela própria instruída pela ortodoxia neoliberal das elites financeiras. O PT fracassou, portanto, em se colocar como o partido de classe a que se propunha (SINGER, 2018).

De outro, mesmo os empresários produtivos são sensíveis aos argumentos do consenso neoliberal que se formou internacionalmente. Como pontua Streeck (2012b), o capitalismo é muito mais do que um sistema econômico, é uma cultura e um modo de vida. A coalizão rentista trabalhou ativamente para divulgar críticas ao ensaio desenvolvimentista de Dilma, cooptando empresários para sua agenda. Os efeitos da ofensiva ideológica foram potencializados pela piora nas condições 
objetivas da economia, fruto tanto de condutas pouco férteis (como a priorização das desonerações frente ao investimento público) quanto de uma conjuntura internacional pouco favorável ao crescimento. Devido à desindustrialização, a economia brasileira tornou-se particularmente sensível à desaceleração da economia chinesa e à deterioração dos preços internacionais de commodities que marcaram o período.

Se nos governos Lula o crescimento econômico possibilitou a conciliação dos interesses do povo e do mercado, no governo Dilma esse modelo baseado em elevadas taxas de juros acabou por permitir o sequestro final do Estado pela riqueza financeira. Em um movimento como o sistematizado por Streeck (2014), o aumento da dívida pública tornou os intermediários financeiros capazes de pressionar o governo que passou, cada vez mais, a ter a realização dos interesses do mercado financeiro como seu principal objetivo. Ao mesmo tempo, a mídia oligopolista, financiada e alinhada aos interesses do rentismo, foi capaz de influenciar a opinião pública brasileira no sentido de fazê-la crer que a crise é resultado da irresponsabilidade fiscal e da corrupção. Fatalmente, em 2016, a Emenda Constitucional 55, ao instituir o congelamento dos gastos públicos por vinte anos, acabou por blindar completamente o Estado das demandas populares enquanto assegurava transferência dos recursos públicos para os credores da dívida (STREECK, 2014; DOWBOR, 2017).

Depreende-se que, nas linhas do que propõe Streeck, a tensão entre democracia e capitalismo atinge um ponto de aceleramento intenso da desdemocratização da economia e deseconomização da democracia após a crise de 2008. Se Streeck (2014, p. 17) acredita que estejamos em uma fase tardia da democracia, em que ela se encontra prestes a ser "esterilizada como democracia de massas redistributiva e reduzida a uma combinação de Estado de direito e distração pública”, o impeachment ${ }^{16}$ de Dilma Rousseff e os dois governos que se seguiram, alinhados aos interesses do mercado financeiro, parecem coroar esse processo no Brasil.

\section{CONSIDERAÇÕES FINAIS}

A resposta dos países ricos à Crise de 2008, que privilegiou o salvamento dos bancos em detrimento da proteção do povo, acabou por escancarar os limites do capitalismo democrático europeu. A despeito da globalização, a crise não pareceu exercer impactos mais decisivos sobre a democracia brasileira do que as próprias reformas neoliberais ao longo das últimas décadas. Isso porque o avanço do neoliberalismo no Brasil, ao promover uma precoce desindustrialização e

\footnotetext{
${ }^{16}$ No Brasil, há um debate ainda corrente em torno da terminologia empregada para descrever os eventos de 2016. Enquanto determinados autores fazem uso do termo "impeachment", outros optam por "golpe branco", como fez Noam Chomsky em entrevista para o Instituto Humanitas (2016). Há também discordâncias entre juristas sobre o fato de o impeachment ter ocorrido sem prova de realização de crime de responsabilidade pela presidente. (TARDELLI, 2017). Este artigo não pretende iniciar uma discussão sobre a terminologia e, portanto, opta por utilizar o termo jurídico e político "impeachment" sem, contudo, buscar implicar que este teria ocorrido em condições ordinárias.
} 
aprofundar a financeirização da economia, criou as condições materiais para que o mercado financeiro capturasse o Estado.

Iniciadas na década de 1990, as reformas trabalhistas e da previdência, a elevada taxa de juros, os cortes em gastos sociais e em investimento público tinham como objetivo acatar as demandas do mercado. De forma semelhante ao que se observou na Europa, à medida que esse processo evoluía e desmobilizava as classes trabalhadoras - concentradas cada vez mais em setores de serviços e crescentemente precarizadas e terceirizadas -, a pauta econômica tornou-se cada vez mais distante dos meios de controle democráticos. Ademais, com o apoio da grande mídia nacional, os dependentes de lucro foram capazes de consolidar a narrativa de que o endividamento do Estado era resultado de um excesso de gastos sociais. Criou-se, então, um consenso respaldado pelas elites e a classe média em torno da agenda neoliberal, possibilitando que o direcionamento da política econômica fosse ditado pelo mercado.

Até o primeiro governo Dilma, algum tipo de conciliação entre os interesses do povo e do mercado ainda era possível. Em 2014, porém, esse modelo chegou ao seu limite, quando ficou clara a ruptura do mercado com o governo petista. O impeachment de Dilma e a ascensão de Michel Temer, seguido por um Paulo Guedes que se anuncia como a ponte entre o governo e o mercado financeiro, parece denunciar a fraqueza da democracia brasileira frente aos interesses do capital financeiro. Evidências disso são a Emenda Constitucional 55 e os ataques de Guedes à previdência, à legislação trabalhista e à iniciativa estatal que escancaram a desconexão entre a política econômica e as demandas por melhores condições de vida e trabalho do povo.

Nesse sentido, a crise político-econômica que culminou na eleição de Bolsonaro parece representar o ápice do longo processo de simultânea desdemocratização da economia e de deseconomização da democracia. Trata-se do divórcio entre a justiça social e a justiça de mercado promovida por décadas de importação da doutrina neoliberal e da ação predatória das elites financeiras nacionais e internacionais.

Não poderia ser diferente. O capitalismo se organiza como uma teia de forças, enquadramentos institucionais, racionalidades pré-fixadas, mentalidades, condicionamentos. Em que se pese a distância geográfica entre o Brasil e os países centrais, ou o tipo de capitalismo, a maneira como ele se institui como modelo econômico, histórico, de política e de estilo de vida implica determinadas consequências mais ou menos gerais. Estas se expressam na tensão entre capitalismo e democracia, ou entre interesses sociais, baseados em noções do que é bom e justo, e a economia de mercado, orientada pela produtividade marginal. Expressam-se, sobretudo, no impacto profundo dos mercados capitalistas sobre estruturas sociais.

Exemplificam primorosamente esse processo a desarticulação progressiva da classe trabalhadora brasileira frente à neoliberalização, o fracasso do Partido dos Trabalhadores em promover uma política econômica coerente com o programa que o elegeu em 2002 e a posição dúbia ocupada pela burguesia industrial brasileira na defesa da produção nacional - para a qual Fernando 
Henrique Cardoso (1972) já apontava em 1964. A análise do caso brasileiro sob a luz de Streeck parece ressaltar as dinâmicas comuns responsáveis pelas trajetórias paralelas de diferentes sociedades capitalistas. Como argumenta Streeck (2011b), é preciso abandonar modelos que preconizam sistemas capitalistas nacionais, completos, simétricos e, portanto, comparáveis, em favor de um que, a despeito das variações e especificidades nacionais ou regionais, seja capaz de situá-las no quadro mais amplo de sua história e da interdependência internacional, econômica e política que caracteriza o sistema capitalista global. Ao examinar a lógica similar pela qual se procedem a desdemocratização da economia no Brasil e na Europa (e suas consequências), este artigo pretende-se um passo inicial nessa direção.

*Artigo recebido em 10 de agosto de 2020, aprovado em 16 de setembro de 2020.

\section{REFERÊNCIAS}

ARAUJO, Cicero; BRESSER-PEREIRA, Luiz Carlos. Para Além do Capitalismo Neoliberal: As Alternativas Políticas. Dados, v. 61, n. 3, p. 551-579, 2018.

BOITO JR, Armando. As relações de classe na nova fase do neoliberalismo no Brasil. In: CAETANO, G.; MAYA, ML (org.). Sujetos sociales y nuevas formas de protesta en la historia reciente de América Latina. Buenos Aires: CLACSO Libros, p. 271-296, 2006.

BRESSER-PEREIRA, Luiz Carlos. A construção política do Brasil: sociedade, economia e Estado desde a Independência. 3a ed. São Paulo: Editora 34, 2016.

BRESSER-PEREIRA, Luiz Carlos. A crise financeira global e depois: um novo capitalismo?. Novos estudos CEBRAP, n. 86, p. 51-72, 2010.

BRESSER-PEREIRA, Luiz Carlos. A lógica perversa da estagnação: dívida, déficit e inflação no Brasil. Revista Brasileira de Economia, v. 45, n. 2, p. 187-212, 1991.

BRESSER-PEREIRA, Luiz Carlos. Modernidade neoliberal. Revista Brasileira de Ciências Sociais, v. 29, n. 84, p. 87-102, 2014.

BRESSER-PEREIRA, Luiz Carlos; OREIRO, José Luis; MARCONI, Nelson. Macroeconomia Desenvolvimentista: Teoria e política econômica do novo desenvolvimentismo. Rio de Janeiro: Elsevier Brasil, 2016.

BRUNO, M. et al. Finance-Led Growth Regime no Brasil: estatuto teórico, evidências empíricas e consequências macroeconômicas. Brazilian Journal of Political Economy, v. 31, n. 5, p. 730750, 2011.

BRUNO, Miguel. Financeirização e crescimento econômico: o caso do Brasil. ComCiência, n. 128, p. O-O, 2011. 
BRUNO, Miguel; PAULANI, Leda. Developmentalist policies in financialized economies: contradictions and impasses of the Brazilian case. In: Workshop of New Developmentalism: Theory and Policy for Developing Countries, 4, 2019, São Paulo. Disponível em: < https://cnd.fgv.br/sites/cnd.fgv.br/files/Miguel_Bruno_VF.pdf>. Acesso em 3 ago. 2020.

CARVALHO, Laura. Valsa brasileira: do boom ao caos econômico. Editora Todavia SA, 2018.

CHANG, Ha-Joon; GRABEL, Ilene. Reclaiming development: An alternative economic policy manual. Zed Books Ltd., 2014.

CARDOSO, Fernando Henrique. Empresário industrial e desenvolvimento econômico no Brasil. Difusão Européia do Livro, 1972.

DOWBOR, Ladislau. A era do capital improdutivo. São Paulo: Autonomia Literária, 2017.

GREMAUD, Amaury P.; SAES, Flávio A. M de e TONETO JR., Rudinei. Formação Econômica do Brasil. São Paulo: Atlas, 1997.

GRIFFITH-JONES, Stephany; SUNKEL, Osvaldo. O fim de uma ilusão: as crises da dívida e do desenvolvimento na América Latina. São Paulo: Brasiliense, 1990.

HARVEY, David. Introduction. In HARVEY, David (Ed.) A Brief History of Neoliberalism. Nova Iorque: Oxford University Press, 2007, 1-5.

KALECKI, Michal. Political aspects of full employment. The political quarterly, v. 14, n. 4, p. 322330, 1943.

MACIEL, David. O governo Collor e o neoliberalismo no Brasil (1990-1992). Revista UFG, v. 13, n. 11, 2011.

MORGAN, Marc. Extreme and persistent inequality: New evidence for Brazil Combining National accounts, surveys and fiscal data, 2001-2015. World Inequality Lab Working Papers, 12, 2017.

OREIRO, José Luis. A grande recessão brasileira: diagnóstico e uma agenda de política econômica. Estudos Avançados, v. 31, n. 89, p. 75-88, 2017.

OREIRO, José Luis; D’AGOSTINI, Luciano. Macroeconomic policy regimes, real exchange rate overvaluation, and performance of the Brazilian economy (2003-2015). Journal of Post Keynesian Economics, v. 40, n. 1, p. 27-42, 2017

"O QUE está acontecendo no Brasil é um golpe branco'". Entrevista com Noam Chomsky. Instituto Humanitas Unisinos, 7 jun. 2016. Disponível em: $<$ http://www.ihu.unisinos.br/noticias/556051qo-que-esta-acontecendo-no-brasil-e-um-golpe-brancoq-entrevista-com-noam-chomsky $>$. Acesso em: 9 set. 2020.

PIKETTY, Thomas. O crescimento: ilusões e realidades. In PIKETTY, Thomas (Ed.) O capital no século XXI. Rio de Janeiro: Editora Intrínseca, 2014, 163-243.

RODRIGUES, João. Streeck, Wolfgang (2013), Tempo comprado-A crise adiada do capitalismo democrático. Revista Crítica de Ciências Sociais, n. 101, p. 153-157, 2013.

SINGER, André. Cutucando onças com varas curtas: o ensaio desenvolvimentista no primeiro mandato de Dilma Rousseff (2011-2014). Novos estudos CEBRAP, n. 102, p. 39-67, 2015. 
SINGER, André. O lulismo em crise: um quebra-cabeça do período Dilma (2011-2016). Editora Companhia das Letras, 2018. Edição Kindle.

STREECK, Wolfgang; SCHMTTER, P. From national corporatism to transnational pluralism: organized interests in the single European market. Politics \& Society, v. 19, n. 2, p. 133-164, 1991.

STREECK, Wolfgang. Taking capitalism seriously: towards an institutionalist approach to contemporary political economy. Socio-Economic Review, v. 9, n. 1, p. 137-167, 2011a.

STREECK, Wolfgang. E pluribus unum? Varieties and commonalities of capitalism. The sociology of economic life, v. 3, p. 419-455, 2011b.

STREECK, Wolfgang. As crises do capitalismo democrático. Novos estudos CEBRAP, n. 92, p. 35-56, 2012a.

STREECK, Wolfgang. How to study contemporary capitalism?. European Journal of Sociology/Archives Européennes de Sociologie, v. 53, n. 1, p. 1-28, 2012b.

STREECK, Wolfgang. Buying time: The delayed crisis of democratic capitalism. Verso Books, 2014.

TARDELLI, Brenno. Análise: Dilma Rousseff foi afastada do cargo sem ter cometido crime de responsabilidade. Justificando, 31 ago.2017. Disponível em: <https://www.justificando.com/2017/o8/31/dilma-rousseff-foi-afastada-do-cargo-sem-tercometido-crime-de-responsabilidade/>. Acesso em: 9 set. 2020. 